\title{
Stereoselective Synthesis of Unnatural $\alpha$-Amino Acids through Photoredox Catalysis
}

Andrey Shatskiy, ${ }^{+}$Anton Axelsson, ${ }^{+}$Björn Blomkvist, ${ }^{+}$Jian-Quan Liu, ${ }^{+}$Peter Dinér, ${ }^{\dagger}$ and Markus D. Kärkäs*, ${ }^{+}$

+ Department of Chemistry, KTH Royal Institute of Technology, SE-100 44 Stockholm, Sweden

\section{Abstract}

A protocol for stereoselective $C$-radical addition to a chiral glyoxylate-derived sulfinyl imine was developed through visible light-promoted photoredox catalysis, providing a convenient method for the synthesis of unnatural $\alpha$-amino acids. The developed protocol allows the use of ubiquitous carboxylic acids as radical precursors without prior derivatization. The protocol utilizes nearstoichiometric amounts of the imine and the acid radical precursor in combination with a catalytic amount of an organic acridinium-based photocatalyst. The mechanism for the developed transformation is discussed and the stereodetermining radical addition step was studied by the DFT calculations.

Keywords: amino acids, carboxylic acids, decarboxylation, organic photocatalyst, photoredox catalysis, stereoselective synthesis 


\section{Introduction}

Unnatural $\alpha$-amino acids constitute an important class of biologically relevant compounds that are widely used in both pharmaceutical industry and fundamental research. ${ }^{1}$ A number of pharmaceuticals based on unnatural $\alpha$-amino acids are currently on the market, including ACE inhibitors for the treatment of cardiovascular and renal diseases, ${ }^{2}$ antiviral medicines, ${ }^{3}$ and others. ${ }^{4}$ Most recently, several drug target studies addressing the globally threatening respiratory disease COVID-19 caused by the SARS-CoV-2 coronavirus were released. ${ }^{5}$ Therein, a number of unnatural $\alpha$ amino acid-based drug candidates were identified, in particular peptidomimetic $\alpha$-ketoamide inhibitors, demonstrating the high demand for such building blocks in the present time.

A variety of synthetic strategies to access unnatural amino acid derivatives have been developed over the years, with some notable methods being the catalytic asymmetric Strecker-type reactions, asymmetric hydrogenation of dehydroamino acids, and electrophilic and nucleophilic alkylation of glycine derivatives (Figure 1 ). ${ }^{6}$ Among these, functionalization or reduction of $\alpha$-imino esters offers a straightforward route to various enantiomerically enriched $\alpha$-amino acids. ${ }^{7}$ Traditionally, these strategies have employed polar retrosynthetic disconnections, which often require the use of (super)stoichiometric amounts of toxic and highly sensitive reagents at low temperatures, thereby limiting the substrate scope and practicality for scale up of these reactions. These limitations have recently been challenged by re-introduction of free radical reaction manifolds, aided by developments in base-metal catalysis, ${ }^{8}$ electrosynthesis ${ }^{9}$ and photoredox catalysis. ${ }^{10}$ Radical addition to imines through photoredox catalysis was recently demonstrated in symmetric ${ }^{11}$ and asymmetric ${ }^{12}$ fashion. In 2017, Alemán and co-workers reported a protocol for asymmetric radical addition to imines mediated by visible light. ${ }^{12}$ The developed catalytic system made use of a chiral sulfoxide auxiliary group, commonly employed in the synthesis of chiral amines. ${ }^{13}$ Here, the $C$-centered radical was generated through visible light-mediated reductive cleavage of the $\mathrm{N}-\mathrm{O}$ bond in a redox-active phthalimide ester, followed by radical addition to the sulfinyl imine. The reductive nature of the 
protocol necessitates a stoichiometric amount of a reducing agent (Hanztsch ester) to be used. More recently, a related Ni-based catalytic system was described by Baran and co-workers. ${ }^{14}$ This protocol also employed a redox-active ester as the radical precursor, with $\mathrm{Zn}$ as a stoichiometric reducing agent and a Ni-based catalyst for mediating the $\mathrm{C}-\mathrm{C}$ bond formation. Although this protocol displayed an impressive substrate scope, it is associated with moderate atom-economy, limiting its applicability for large-scale synthesis.

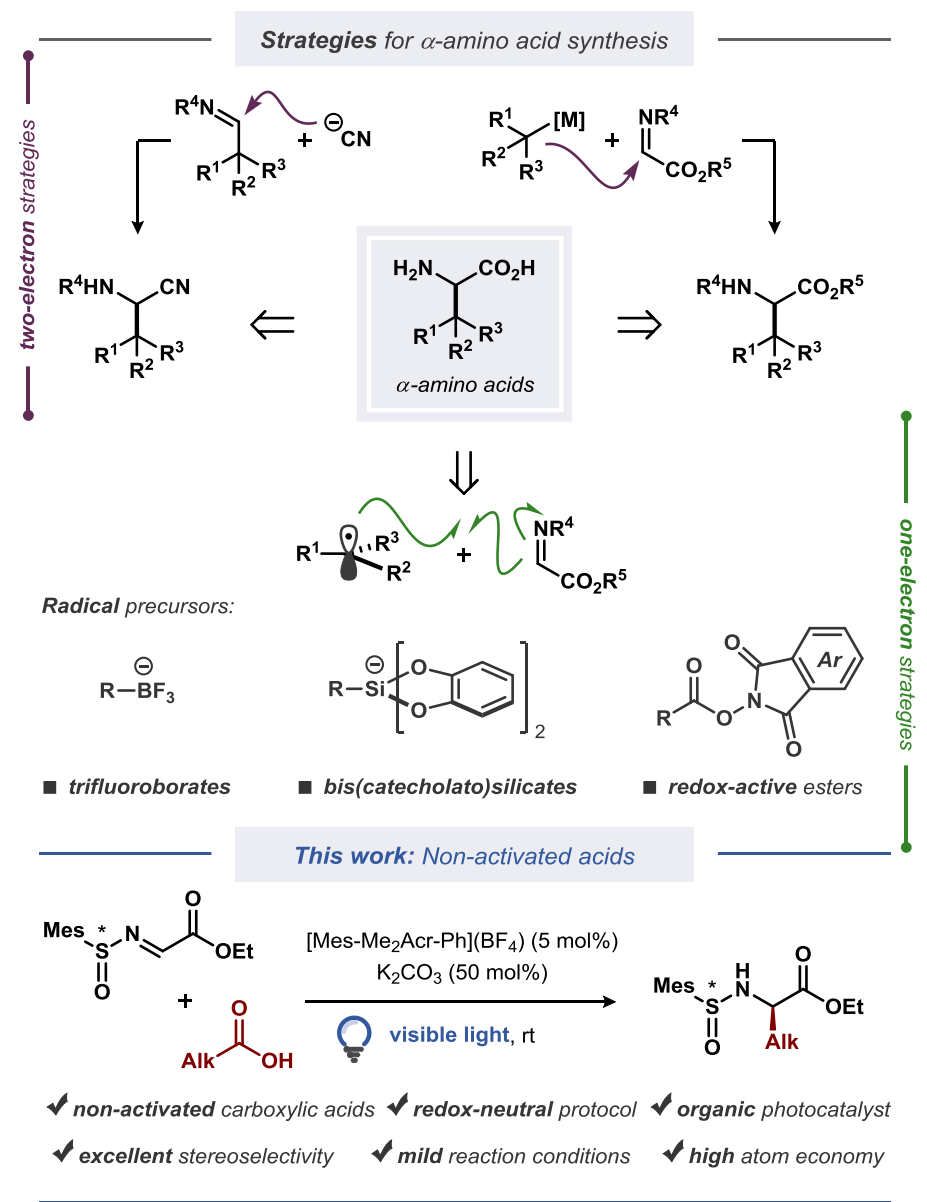

Figure 1. Strategies for synthesis of unnatural $\alpha$-amino acids (top), and diastereoselective decarboxylative alkylation of sulfinyl imines with non-activated carboxylic acids (bottom).

\section{Results and Discussion}

Inspired by the catalytic systems developed by the Alemán, ${ }^{12} \mathrm{Ye},{ }^{11 \mathrm{a}}$ and Baran ${ }^{13}$ groups, we sought to realize a protocol for diastereoselective decarboxylative radical addition to chiral sulfinyl imines that 
would utilize ubiquitous non-activated carboxylic acids as radical precursors. ${ }^{15} \mathrm{~A}$ related direct decarboxylative addition process was attempted by the Alemán group for a benzaldehyde-derived sulfinyl imine under reaction conditions reported by MacMillan; ${ }^{16}$ however, no formation of the desired product was observed (see the Supporting Information to ref. 12). Similarly, we observed no desired product with pivalic acid $2 \mathbf{a}$ as the radical precursor and sulfinyl imine $\mathbf{1}$ as the radical acceptor when the reaction was conducted in DMSO with $\left[\operatorname{Ir}\left(\mathrm{dF}\left(\mathrm{CF}_{3}\right) \text { ppy }\right)_{2}(\mathrm{dtbbpy})\right]\left(\mathrm{PF}_{6}\right)$ as photocatalyst (Table 1, entry 1), presumably due to fast decomposition of sulfinyl imine 1 . Gratifyingly, changing the solvent to $\alpha, \alpha, \alpha$-trifluorotoluene $\left(\mathrm{PhCF}_{3}\right)$ furnished the desired product 3a in fairly good yield of $65 \%$, although with poor diastereoselectivity (Table 1, entry 2). Using other bases in place of $\mathrm{Cs}_{2} \mathrm{CO}_{3}$ completely prohibited the reaction (for details on the optimization studies, see the Supporting Information), and the highly-oxidizing photocatalyst 4CzIPN ${ }^{17}$ failed to deliver the radical addition product (Table 1, entry 3). Fortunately, the highly-oxidizing organic acridinium-based photocatalyst [Mes-Acr-Me] $\left(\mathrm{BF}_{4}\right)$ delivered product 3a with excellent diastereoselectivity, although in poor yield (Table 1, entry 4). Increasing the catalyst loading from 1 to $5 \mathrm{~mol} \%$ and switching to the more stable $\mathrm{N}$-phenyl-substituted photocatalysts [Mes-Acr-Ph] $\left(\mathrm{BF}_{4}\right)$ and $\left[\mathrm{Mes}-\mathrm{Me}_{2} \mathrm{Acr}-\mathrm{Ph}\right]\left(\mathrm{BF}_{4}\right)^{18}$ dramatically increased the yield of the stereoselective radical addition product up to $78 \%$ (Table 1, entries 5-7). Changing the base to $\mathrm{K}_{2} \mathrm{CO}_{3}$ and increasing the base loading further improved the yield up to $85 \%$ (Table 1 , entry 11 ). Finally, utilizing a slight excess of the acid radical precursor $2 a$ delivered the desired product 3a in excellent yields (91\% and $95 \%$ for 1.2 and 1.5 equiv. of $\mathbf{2 a}$, respectively; Table 1 , entries 13 and 14). Consistently with the previous reports on radical additions to sulfinyl imines, the tert-butyl- and para-tolyl-substituted sulfinyl imines $\mathbf{4}$ and $\mathbf{5}$ proved to be inefficient as radical acceptors (Table 1, entries 15 and 16). ${ }^{12,14}$ In case of tert-butyl-substituted sulfinyl imine $\mathbf{4}$, it is likely that the transiently formed 
Table 1. Optimization of the reaction conditions for the decarboxylative radical addition to a glyoxylatederived sulfinyl imine. ${ }^{a}$
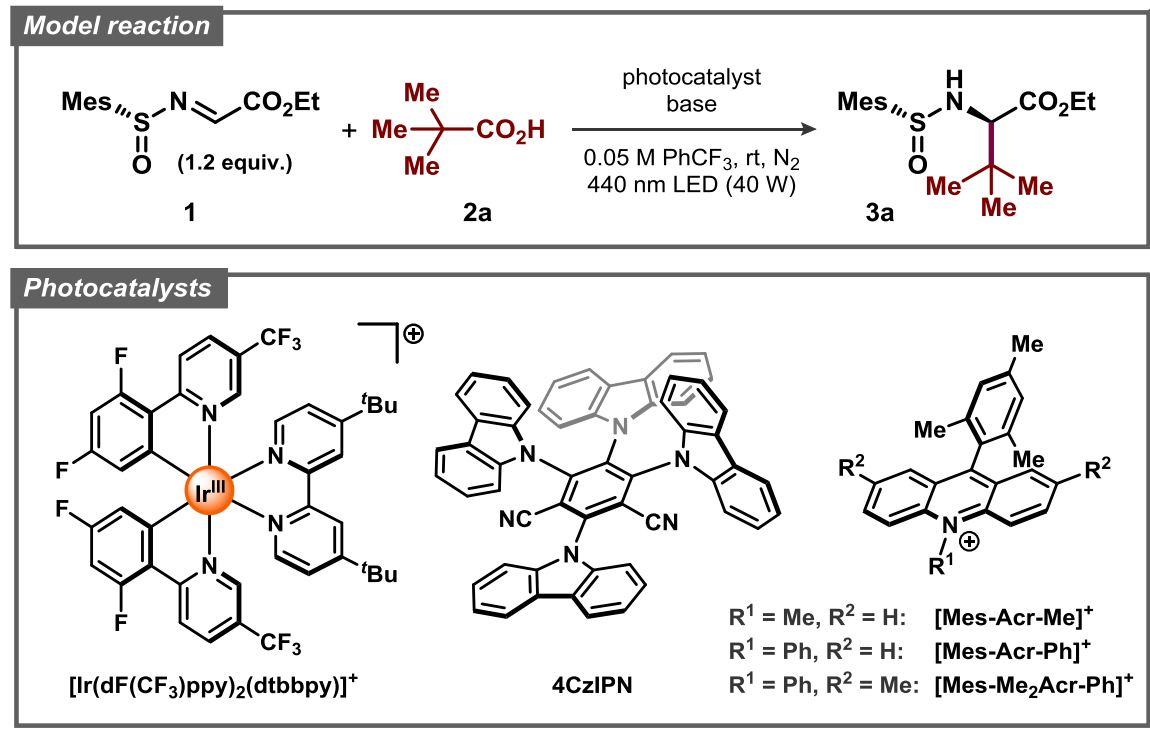

\begin{tabular}{|c|c|c|c|c|c|}
\hline entry & photocatalyst & base & time & yield ${ }^{b}$ & $d r^{b}$ \\
\hline $\mathbf{1}^{c}$ & $\begin{array}{l}{\left[\operatorname{Ir}\left(\mathrm{dF}\left(\mathrm{CF}_{3}\right) \mathrm{ppy}\right)_{2}(\mathrm{dtbbpy})\right]\left(\mathrm{PF}_{6}\right),} \\
1 \mathrm{~mol} \%\end{array}$ & $\mathrm{Cs}_{2} \mathrm{CO}_{3}, 0.2$ equiv. & $20 \mathrm{~min}$ & $<5 \%$ & - \\
\hline 2 & $\begin{array}{l}{\left[\operatorname{Ir}\left(\mathrm{dF}\left(\mathrm{CF}_{3}\right) \mathrm{ppy}\right)_{2}(\mathrm{dtbbpy})\right]\left(\mathrm{PF}_{6}\right),} \\
1 \mathrm{~mol} \%\end{array}$ & $\mathrm{Cs}_{2} \mathrm{CO}_{3}, 0.2$ equiv. & $20 \mathrm{~min}$ & $65 \%$ & $4: 1$ \\
\hline 3 & 4CzIPN, 1 mol\% & $\mathrm{Cs}_{2} \mathrm{CO}_{3}, 0.2$ equiv. & $20 \mathrm{~min}$ & $<5 \%$ & - \\
\hline 4 & {$[\mathrm{Mes}-\mathrm{Acr}-\mathrm{Me}]\left(\mathrm{BF}_{4}\right), 1 \mathrm{~mol} \%$} & $\mathrm{Cs}_{2} \mathrm{CO}_{3}, 0.2$ equiv. & $20 \mathrm{~min}$ & $27 \%$ & $>95: 5$ \\
\hline 5 & {$[\mathrm{Mes}-\mathrm{Acr}-\mathrm{Me}]\left(\mathrm{BF}_{4}\right), 5 \mathrm{~mol} \%$} & $\mathrm{Cs}_{2} \mathrm{CO}_{3}, 0.2$ equiv. & & $\begin{array}{l}48 \% \\
66 \%\end{array}$ & $\begin{array}{l}>95: 5 \\
>95: 5\end{array}$ \\
\hline 6 & [Mes-Acr-Ph] $\left(\mathrm{BF}_{4}\right), 5 \mathrm{~mol} \%$ & $\mathrm{Cs}_{2} \mathrm{CO}_{3}, 0.2$ equiv. & $60 \mathrm{~min}$ & $73 \%$ & $>95: 5$ \\
\hline 7 & {$\left[\mathrm{Mes}-\mathrm{Me}_{2} \mathrm{Acr}-\mathrm{Ph}\right]\left(\mathrm{BF}_{4}\right), 5 \mathrm{~mol} \%$} & $\mathrm{Cs}_{2} \mathrm{CO}_{3}, 0.2$ equiv. & $60 \mathrm{~min}$ & $78 \%$ & $>95: 5$ \\
\hline 8 & {$\left[\mathrm{Mes}-\mathrm{Me}_{2} \mathrm{Acr}-\mathrm{Ph}\right]\left(\mathrm{BF}_{4}\right), 5 \mathrm{~mol} \%$} & $\mathrm{~K}_{3} \mathrm{PO}_{4}, 0.2$ equiv. & $60 \mathrm{~min}$ & $80 \%$ & $>95: 5$ \\
\hline 9 & {$\left[\mathrm{Mes}-\mathrm{Me}_{2} \mathrm{Acr}-\mathrm{Ph}\right]\left(\mathrm{BF}_{4}\right), 5 \mathrm{~mol} \%$} & $\mathrm{~K}_{2} \mathrm{CO}_{3}, 0.2$ equiv. & $60 \mathrm{~min}$ & $84 \%$ & $>95: 5$ \\
\hline 10 & {$\left[\mathrm{Mes}-\mathrm{Me}_{2} \mathrm{Acr}-\mathrm{Ph}\right]\left(\mathrm{BF}_{4}\right), 5 \mathrm{~mol} \%$} & $\mathrm{~K}_{2} \mathrm{CO}_{3}, 0.05$ equiv. & $20 \mathrm{~min}$ & $<5 \%$ & - \\
\hline 11 & {$\left[\mathrm{Mes}-\mathrm{Me}_{2} \mathrm{Acr}-\mathrm{Ph}\right]\left(\mathrm{BF}_{4}\right), 5 \mathrm{~mol} \%$} & $\mathrm{~K}_{2} \mathrm{CO}_{3}, 0.5$ equiv. & $60 \mathrm{~min}$ & $85 \%$ & $>95: 5$ \\
\hline $12^{d}$ & {$\left[\mathrm{Mes}-\mathrm{Me}_{2} \mathrm{Acr}-\mathrm{Ph}\right]\left(\mathrm{BF}_{4}\right), 5 \mathrm{~mol} \%$} & $\mathrm{~K}_{2} \mathrm{CO}_{3}, 0.5$ equiv. & $60 \mathrm{~min}$ & $77 \%$ & $>95: 5$ \\
\hline $13^{e}$ & {$\left[\mathrm{Mes}-\mathrm{Me}_{2} \mathrm{Acr}-\mathrm{Ph}\right]\left(\mathrm{BF}_{4}\right), 5 \mathrm{~mol} \%$} & $\mathrm{~K}_{2} \mathrm{CO}_{3}, 0.5$ equiv. & $60 \mathrm{~min}$ & $91 \%$ & $>95: 5$ \\
\hline $14^{f}$ & {$\left[\mathrm{Mes}-\mathrm{Me}_{2} \mathrm{Acr}-\mathrm{Ph}\right]\left(\mathrm{BF}_{4}\right), 5 \mathrm{~mol} \%$} & $\mathrm{~K}_{2} \mathrm{CO}_{3}, 0.5$ equiv. & $60 \mathrm{~min}$ & $95 \%$ & $>95: 5$ \\
\hline 15 & \multicolumn{2}{|c|}{ As entry 13 , but with ${ }^{t} \mathrm{Bu}$-sulfinyl imine 4} & $60 \mathrm{~min}$ & $<5 \%$ & - \\
\hline 16 & \multicolumn{2}{|c|}{ As entry 13 , but with $p$-Tol-sulfinyl imine 5} & $60 \mathrm{~min}$ & $50 \%$ & $7: 1$ \\
\hline
\end{tabular}

\section{deviations from the conditions in entry 13}

\begin{tabular}{|c|c|c|c|}
\hline 17 under air & $60 \mathrm{~min}$ & $12 \%$ & $>95: 5$ \\
\hline 18 no photocatalyst & $60 \mathrm{~min}$ & $<5 \%$ & - \\
\hline 19 no light & $60 \mathrm{~min}$ & $<5 \%$ & \\
\hline
\end{tabular}

${ }^{a}$ The reactions were performed on $0.1 \mathrm{mmol}$ scale: stock solutions of the pivalic acid 2 and the photocatalyst (each in $1 \mathrm{~mL}$ of the solvent) were mixed with the sulfinyl imine $\mathbf{1}$ and the base under anhydrous conditions, and stirred under irradiation with $440 \mathrm{~nm}$ blue LED light at room temperature (for details, see the Supporting Information). ${ }^{b}$ Determined by ${ }^{1} \mathrm{H}$ NMR of a crude reaction mixture with 1,3,5-trimethoxybenzene as an internal standard. ${ }^{c} 0.1 \mathrm{M}$ DMSO. ${ }^{d} 0.1 \mathrm{M} \mathrm{PhCF}_{3}{ }^{e} 1.0$ equiv. of sulfinyl imine 1 and 1.2 equiv. of pivalic acid $2 .{ }^{f} 1.0$ equiv. of sulfinyl imine 1 and 1.5 equiv. of pivalic acid 2. 
aminyl radical intermediate underwent decomposition to form an iminosulfanone $(-\mathrm{N}=\mathrm{S}=\mathrm{O})$, thereby disrupting the catalytic cycle. ${ }^{19}$

The substrate scope of the developed transformation was evaluated with a variety of commercially available tertiary, secondary, and primary carboxylic acids (Figure 2). For all of the amino acid derivatives, except product $\mathbf{3 f}$, excellent diastereoselectivity at the $\alpha$-position was observed (>95:5 $d r$ ). The unfunctionalized tertiary carboxylic acids $\mathbf{2 a}$ and $\mathbf{2} \mathbf{c}$ delivered the radical addition products $\mathbf{3 a}$ and $\mathbf{3 c}$ in high yields ( $81 \%$ and $87 \%$, respectively). The potentially oxidatively sensitive gemfibrozil-derived product $\mathbf{3 b}$ could also be accessed, although in lower yield (44\%). Surprisingly, $\mathrm{N}$-Boc-piperidine-derived product $\mathbf{3 d}$ was obtained in relatively low yield (33\%), while oxetane- and cyclopropyl-containing carboxylic acids $\mathbf{2} \mathbf{e}$ and $\mathbf{2} \mathbf{f}$ delivered the corresponding products $\mathbf{3 e}$ and $\mathbf{3} \mathbf{f}$ in moderate yields ( $54 \%$ and $52 \%$, respectively). The cyclohexyl radical addition adduct $\mathbf{3 h}$ was obtained in high yield (73\%), while other non-stabilized secondary and primary carboxylic acids 21-k provided lower yields compared to the tertiary acids, consistent with previous reports featuring secondary and primary free radical intermediates under related conditions. ${ }^{20}$ Further optimization of the reaction conditions for the primary acids $\mathbf{2} \mathbf{j}$ and $\mathbf{2} \mathbf{k}$ did not result in improved yields (Tables S2 and S3), illustrating the intrinsic instability of the respective radical intermediates and/or the photocatalyst under the employed conditions.

Next, we surveyed carboxylic acid radical precursors that furnish stabilized $\alpha$-heteroatom $C$ radicals. Gratifyingly, $N$-Boc-protected $\alpha$-amino acid radical precursors based on pipecolic acid, proline, valine, and phenylalanine provided the expected amino acid derivatives $\mathbf{3 1 - 0}$ in generally excellent yields (up to $>99 \%$ ), exemplifying a prominent synthetic route to biologically active $\alpha, \beta$ diamino acids. ${ }^{21}$ The $\alpha$-O-substituted radicals derived from tetrahydro-2-furonic and methoxymandelic acids provided the expected radical addition products $3 p$ and $3 \mathbf{q}$ in $45 \%$ and $60 \%$ yields, respectively. A tertiary $\alpha$-O-substituted radical derived from clofibric acid $\mathbf{2 g}$ delivered product $\mathbf{3 g}$ in excellent yield (90\%). Interestingly, products $\mathbf{3 n - q}$ were obtained not only with 
excellent diastereoselectivity at the $\alpha$-position ( $>95: 5 d r$ ), but also with a slight diastereoselectivity at the $\beta$-position (up to $1.5: 1 \mathrm{dr}$ ). In general, the acids with strong electron-withdrawing substituents at the $\alpha$-position $\left(\mathrm{CF}_{3}\right.$, benzyl, and benzoyl) did not provide the desired products, likely due to the insufficient nucleophilic character of the formed $C$-radicals (see the unsuccessful substrates in Figure 2). The $\alpha-H$ and $\alpha$-Me-substituted cyclopropanecarboxylic acids were also inefficient, despite successful reaction with the analogous $\alpha$-Ph-substituted substrate $\mathbf{2 f}$.

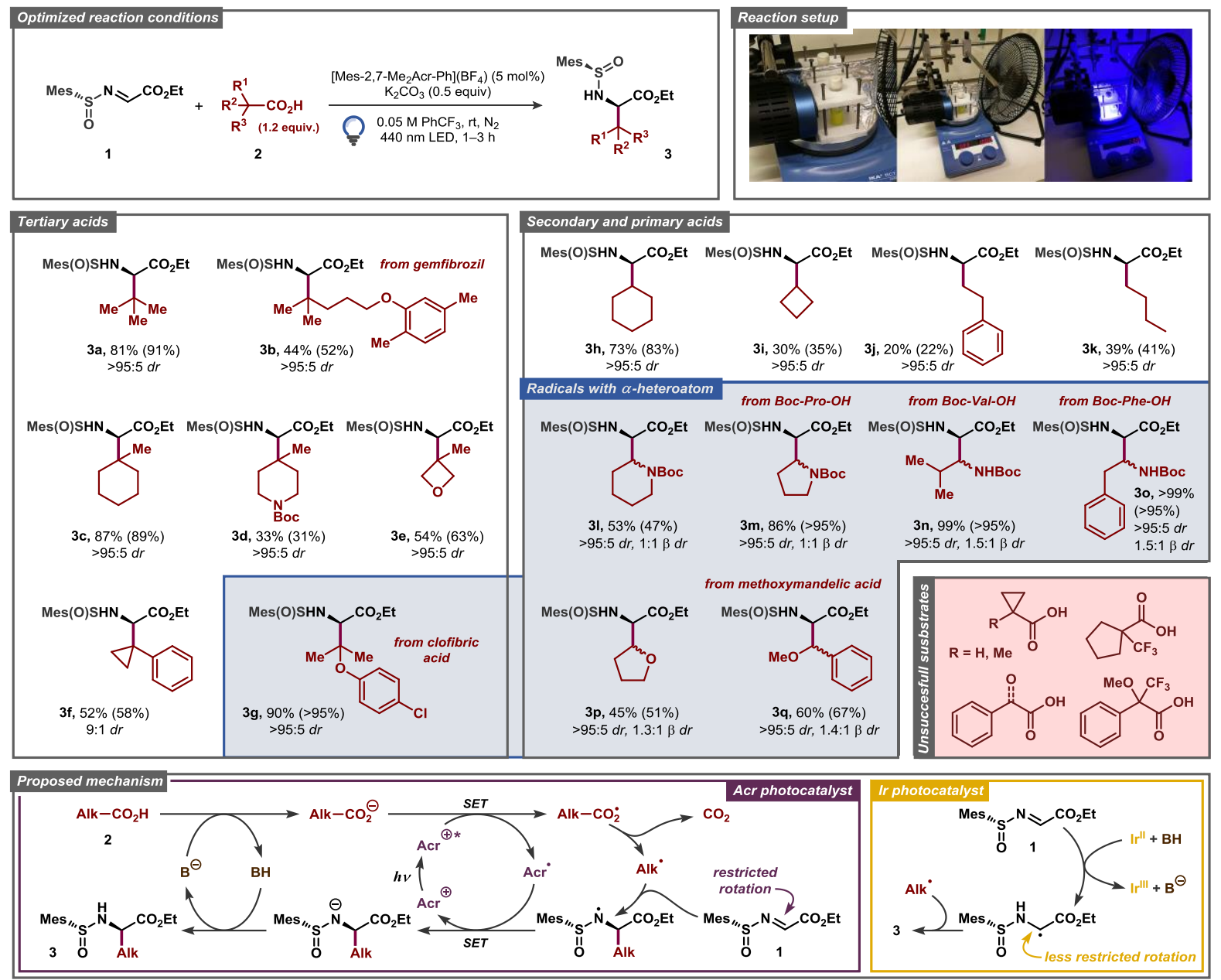

Figure 2. Substrate scope for the decarboxylative radical addition to glyoxylate-derived sulfinyl imine $\mathbf{1}$ to furnish the unnatural amino acid precursors 3. The isolated yields of the products and NMR-yields from the crude reaction mixtures (in parenthesis) are reported (see the Supporting Information for details). ${ }^{a} 1 \mathrm{mmol}$ scale reaction. 
Based on previous literature precedents, a mechanism for the developed transformation was proposed (Figure 2, bottom). ${ }^{12,22}$ Initially, the acridinium photocatalyst [Mes-Me $\left.\mathrm{Acr}-\mathrm{Ph}\right]\left(\mathrm{BF}_{4}\right)\left(\mathrm{Acr}^{+}\right)$ is excited by visible light $\left(\lambda_{\max } \approx 425 \mathrm{~nm}\right)$ to a highly oxidizing excited state $\operatorname{Acr}^{+*}\left(E\left(\mathrm{Acr}^{+} * / \mathrm{Acr}^{\circ}\right) \approx 2.09\right.$ V vs. SCE). ${ }^{23}$ In this state, the photocatalyst can abstract an electron from the deprotonated carboxylic acid via a single-electron transfer (SET) event to generate a carboxylate radical while being reduced to the acridinium radical Acr. The carboxyl radical then extrudes $\mathrm{CO}_{2}$ to form a $\mathrm{C}$ centered radical, which undergoes addition to the sulfinyl imine $\mathbf{1}$ in the key step of the reaction, forming an $\alpha$-alkylated $\mathrm{N}$-centered radical. Finally, the $\mathrm{N}$-centered radical is reduced by Acr ${ }^{\circ}$, closing the photocatalytic cycle and furnishing the desired product $\mathbf{3}$ upon protonation.

An alternative mechanism for a related radical addition process to imine derivatives was proposed by Ooi and co-workers. ${ }^{24}$ Here, the key $\mathrm{C}-\mathrm{C}$ bond-forming step was found to proceed through radical-radical coupling between a C-centered radical and an azaketyl-type radical. However, under our conditions such a mechanistic pathway seems unlikely due to weak reducing ability of the one-electron reduced form of the employed acridinium photocatalyst $\left(E\left(\mathrm{Acr}^{+} / \mathrm{Acr}^{\circ}\right) \approx\right.$ $-0.58 \mathrm{~V}$ vs. SCE). As opposed to the conditions reported by Ooi and co-workers, where strongly reducing $\left[\operatorname{Ir}(\mathrm{ppy})_{2}(\mathrm{bpy})\right]^{+}$-type photocatalysts $\left(E\left(\mid \mathrm{Ir}^{\prime \prime \prime} / / \mathrm{r}^{\prime \prime}\right) \approx-1.5 \mathrm{~V}\right.$ vs. SCE) were used, electron transfer from Acr to sulfinyl imine 1 ( $E_{\mathrm{p}} \approx-1.1 \mathrm{~V}$ vs. SCE, as determined by cyclic voltammetry) should not be favored. Notably, a shift to an Ooi-type radical-radical coupling pathway could explain the low diastereoselectivity (4:1 dr) during formation of product 3a when the reaction was conducted with the $\left[\operatorname{Ir}\left(\mathrm{dF}\left(\mathrm{CF}_{3}\right) \mathrm{ppy}\right)_{2}(\mathrm{dtbbpy})\right]\left(\mathrm{PF}_{6}\right)$ photocatalyst (Table 1, entry 2; Figure 2, bottom right). The low diastereoselectivity could also be explained by product epimerization during the reaction; however, no epimerization was observed when product $\mathbf{3 a}$ was subjected to the comparable reaction conditions.

In order to gain better understanding of the stereodetermining $\mathrm{C}-\mathrm{C}$ bond forming step in the proposed mechanism with acridinium-based photocatalyst DFT calculations were performed on the 
M062X-D3/6-311+G(d,p) level of theory (see the Supporting Information for details). First, the structure of the sulfinyl imine radical acceptor 1 was evaluated. Previously, Alemán and co-workers tentatively suggested an s-cis conformation around the $\mathrm{N}-\mathrm{S}$ bond as being more stable in this compound due to the hydrogen bonding between the imine proton and the sulfoxide oxygen (Figure 3). ${ }^{12}$ Such a conformational preference would then lead to the $\alpha-(R)$ product when the $S(R)$-sulfinyl imine is employed as the radical acceptor. This stereochemical outcome was indeed observed for both Alemán's and our catalytic system. The calculations confirmed that the s-cis conformer is more stable compared to the s-trans by $3.8 \mathrm{kcal} / \mathrm{mol}$, corresponding to $>99.8: 0.2$ ratio between the conformers from the Boltzmann distribution at room temperature. In the s-cis conformer the expected constructive orbital overlap was observed between the imine hydrogen and the sulfoxide oxygen, while for the s-trans conformer the constructive, but weaker, orbital overlap was found between the imine hydrogen and the carbonyl oxygen of the ester group (for a detailed discussion, see the Supporting Information).

Subsequently, the radical addition step was evaluated with the tert-butyl radical donor producing product 3a, and the computed Gibbs free energy diagram for the reaction is presented in Figure 3. The formation of $(R, R)$-diastereomer of $\mathbf{3 a}$ was found to be favored both kinetically and thermodynamically and the computed activation barrier was found to be $3.8 \mathrm{kcal} / \mathrm{mol}$ smaller for the re-addition compared to the si-addition, while the $(R, R)$-diastereomer product is $2.5 \mathrm{kcal} / \mathrm{mol}$ more stable compared to the $(R, S)$-diastereomer. The better stabilization of the re-TS is in part due to the stronger hydrogen bonding between the imine hydrogen and the sulfoxide oxygen for this transition state, as evident from the calculated bond distances and the visualized molecular orbitals (Figure S3). Additionally, significant sterical crowding occurs in the si-TS, where the incoming tertbutyl radical requires the mesityl group to become almost completely coplanar to the sulfoxide $S=0$ bond. In contrast, the mesityl group and the $\mathrm{S}=\mathrm{O}$ bond in the re-TS are out of plane by $50^{\circ}$ while the incoming tert-butyl radical experiences no sterical crowding (Figure 3). 

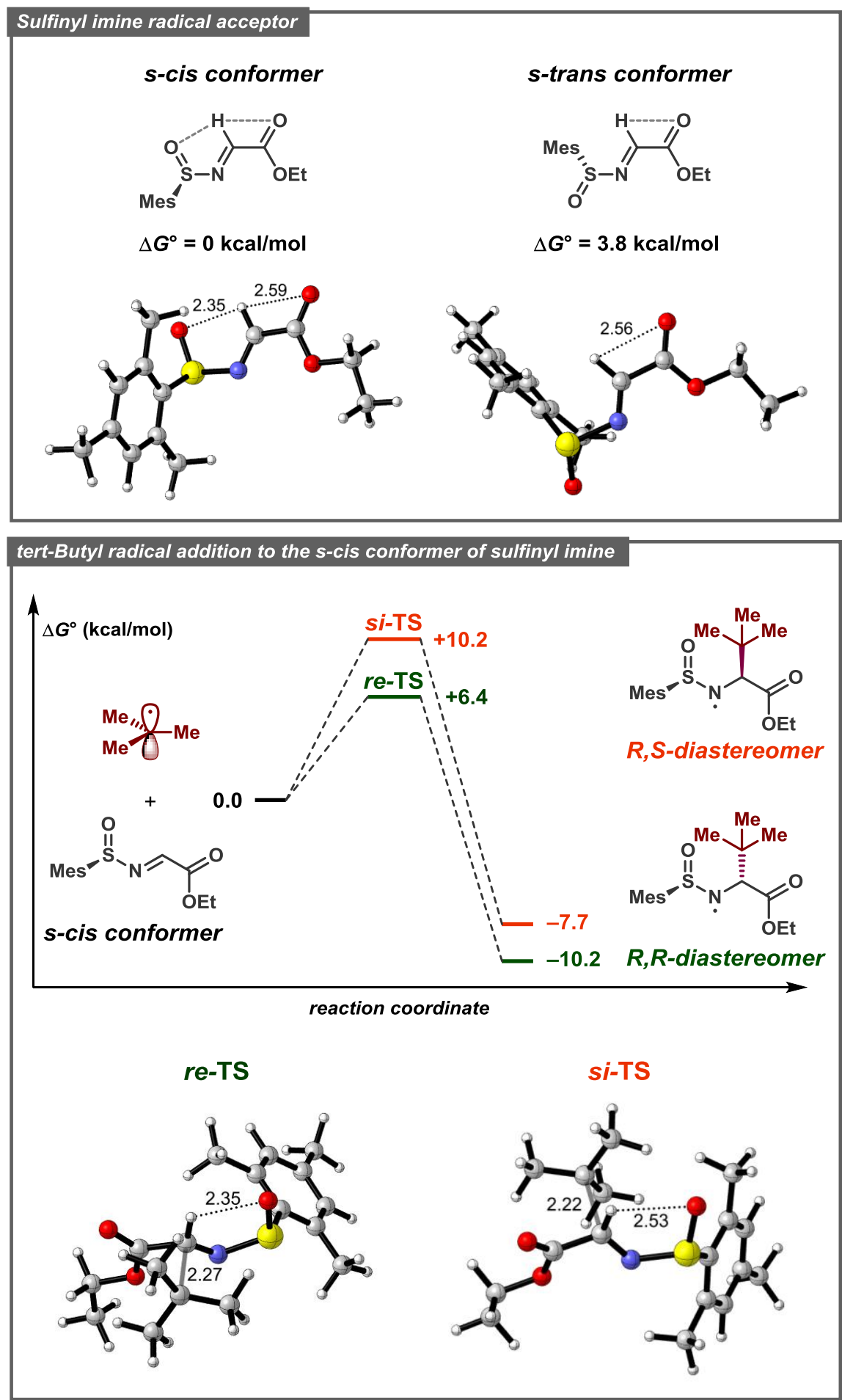

Figure 3. Calculated structures with selected bond distances $(\AA \AA)$ for the s-cis and s-trans isomers of sulfinyl imine 1 (top), Gibbs free energy diagram for tert-butyl radical addition to 1 (middle), and calculated structures for the re-TS and si-TS transition states (bottom). 


\section{Conclusions}

A practical protocol for stereoselective synthesis of various $\alpha$-amino acids has been developed, employing ubiquitous carboxylic acids as radical precursors and an organic photocatalyst under visible light irradiation. This protocol allows for synthesis of highly functionalized $\alpha$-amino acids, which are challenging to prepare through traditional two-electron reaction manifolds. The protocol utilizes near-stoichiometric amounts of reagents and does not produce large quantities of waste, which is an intrinsic disadvantage of the previously described systems utilizing redox-active esters as radical precursors.

\section{ORCID}

Andrey Shatskiy: $\quad 0000-0002-7249-7437$

Anton Axelsson: $\quad$ 0000-0003-0899-2852

Björn Blomkvist: 0000-0001-6026-1921

Jian-Quan Liu: $\quad$ 0000-0002-5533-2075

Peter Dinér: $\quad$ 0000-0001-6782-6622

Markus D. Kärkäs: 0000-0002-6089-5454

\section{Notes}

The authors declare no competing financial interest.

\section{Acknowledgements}

Financial support from KTH Royal Institute of Technology to M.D.K. is gratefully acknowledged. The Olle Engkvists Stiftelse and the Wenner-Gren Foundations are kindly acknowledged for postdoctoral fellowships to A.S. and J.L., respectively. P.D. acknowledges financial support from the Carl Trygger Foundation for a postdoctoral fellowship to A.A. 


\section{References}

(1) (a) Ravikumar, Y.; Nadarajan, S. P.; Yoo, T. H.; Lee, C.; Yun, H. Unnatural Amino Acid Mutagenesis-Based Enzyme Engineering. Trends in Biotechnology 2015, 33, 462-470. (b) Blaskovich, M. A. T. Unusual Amino Acids in Medicinal Chemistry. J. Med. Chem. 2016, 59, 10807-10836. (c) Neumann-Staubitz, P.; Neumann, H. The Use of Unnatural Amino Acids to Study and Engineer Protein Function. Current Opinion in Structural Biology 2016, 38, 119-128.

(2) Arora, P. K.; Chauhan, A. ACE Inhibitors: A Comprehensive Review. International Journal of Pharmaceutical Sciences and Research 2013, 3, 532-549.

(3) De Clercq, E.; Li, G. Approved Antiviral Drugs over the Past 50 Years. Clinical Microbiology Reviews 2016, 29, 695-747.

(4) (a) Miller, L. M.; Pritchard, J. M.; Macdonald, S. J. F.; Jamieson, C.; Watson, A. J. B. Emergence of Small-Molecule Non-RGD-Mimetic Inhibitors for RGD Integrins. J. Med. Chem. 2017, 60, 32413251. (b) Giraud, I.; Rapp, M.; Maurizis, J.-C.; Madelmont, J.-C. Synthesis and in vitro Evaluation of Quaternary Ammonium Derivatives of Chlorambucil and Melphalan, Anticancer Drugs Designed for the Chemotherapy of Chondrosarcoma. J. Med. Chem. 2002, 45, 2116-2119. (c) Ankersen, M.; Johansen, N. L.; Madsen, K.; Hansen, B. S.; Raun, K.; Nielsen, K. K.; Thøgersen, H.; Hansen, T. K.; Peschke, B.; Lau, J.; Lundt, B. F.; Andersen, P. H. A New Series of Highly Potent Growth Hormone-Releasing Peptides Derived from Ipamorelin. J. Med. Chem. 1998, 41, 36993704.

(5) (a) Gordon, D. E.; Jang, G. M.; Bouhaddou, M.; Xu, J.; Obernier, K.; O’Meara, M. J.; Guo, J. Z.; Swaney, D. L.; Tummino, T. A.; Huettenhain, R.; Kaake, R. M.; Richards, A. L.; Tutuncuoglu, B.; Foussard, H.; Batra, J.; Haas, K.; Modak, M.; Kim, M.; Haas, P.; Polacco, B. J.; Braberg, H.; Fabius, J. M.; Eckhardt, M.; Soucheray, M.; Bennett, M. J.; Cakir, M.; McGregor, M. J.; Li, Q.; Naing, Z. Z. C.; Zhou, Y.; Peng, S.; Kirby, I. T.; Melnyk, J. E.; Chorba, J. S.; Lou, K.; Dai, S. A.; Shen, W.; Shi, Y.; Zhang, Z.; Barrio-Hernandez, I.; Memon, D.; Hernandez-Armenta, C.; Mathy, C. J. P.; Perica, T.; Pilla, K. B.; Ganesan, S. J.; Saltzberg, D. J.; Ramachandran, R.; Liu, X.; Rosenthal, S. B.; Calviello, 
L.; Venkataramanan, S.; Liboy-Lugo, J.; Lin, Y.; Wankowicz, S. A.; Bohn, M.; Sharp, P. P.; Trenker, R.; Young, J. M.; Cavero, D. A.; Hiatt, J.; Roth, T. L.; Rathore, U.; Subramanian, A.; Noack, J.; Hubert, M.; Roesch, F.; Vallet, T.; Meyer, B.; White, K. M.; Miorin, L.; Rosenberg, O. S.; Verba, K. A.; Agard, D.; Ott, M.; Emerman, M.; Ruggero, D.; García-Sastre, A.; Jura, N.; von Zastrow, M.; Taunton, J.; Ashworth, A.; Schwartz, O.; Vignuzzi, M.; d'Enfert, C.; Mukherjee, S.; Jacobson, M.; Malik, H. S.; Fujimori, D. G.; Ideker, T.; Craik, C. S.; Floor, S.; Fraser, J. S.; Gross, J.; Sali, A.; Kortemme, T.; Beltrao, P.; Shokat, K.; Shoichet, B. K.; Krogan, N. J. A SARS-CoV-2-Human Protein-Protein Interaction Map Reveals Drug Targets and Potential Drug-Repurposing. bioRxiv 2020, DOI:10.1101/2020.03.22.002386. (b) Zhang, L.; Lin, D.; Sun, X.; Curth, U.; Drosten, C.; Sauerhering, L.; Becker, S.; Rox, K.; Hilgenfeld, R. Crystal Structure of SARS-CoV-2 Main Protease Provides a Basis for Design of Improved $\alpha$-Ketoamide Inhibitors. Science 2020, DOI:10.1126/science.abb3405. (c) Zhang, L.; Lin, D.; Kusov, Y.; Nian, Y.; Ma, Q.; Wang, J.; von Brunn, A.; Leyssen, P.; Lanko, K.; Neyts, J.; de Wilde, A.; Snijder, E. J.; Liu, H.; Hilgenfeld, R. $\alpha-$ Ketoamides as Broad-Spectrum Inhibitors of Coronavirus and Enterovirus Replication: StructureBased Design, Synthesis, and Activity Assessment. J. Med. Chem. 2020, DOI: 10.1021/acs.jmedchem.9b01828. (d) Liu, C.; Zhou, Q.; Li, Y.; Garner, L. V.; Watkins, S. P.; Carter, L. J.; Smoot, J.; Gregg, A. C.; Daniels, A. D.; Jervey, S.; Albaiu, D. Research and Development on Therapeutic Agents and Vaccines for COVID-19 and Related Human Coronavirus Diseases. ACS Cent. Sci. 2020, 6, 315-331.

(6) (a) Nájera, C.; Sansano, J. M. Catalytic Asymmetric Synthesis of $\alpha$-Amino Acids. Chem. Rev. 2007, 107, 4584-4671. (b) Liu, J.-Q.; Shatskiy, A.; Matsuura, B. S.; Kärkäs, M. D. Recent Advances in Photoredox Catalysis Enabled Functionalization of $\alpha$-Amino Acids and Peptides: Concepts, Strategies and Mechanisms. Synthesis 2019, 51, 2759-2791. (c) Ma, J.-A. Recent Developments in the Catalytic Asymmetric Synthesis of $\alpha$ - and $\beta$-Amino Acids. Angew. Chem., Int. Ed. 2003, 42, 4290-4299. 
(7) Eftekhari-Sis, B.; Zirak, M. $\alpha$-Imino Esters in Organic Synthesis: Recent Advances. Chem. Rev. $2017,117,8326-8419$.

(8) (a) Weix, D. J. Methods and Mechanisms for Cross-Electrophile Coupling of Csp ${ }^{2}$ Halides with Alkyl Electrophiles. Acc. Chem. Res. 2015, 48, 1767-1775. (b) Gandeepan, P.; Müller, T.; Zell, D.; Cera, G.; Warratz, S.; Ackermann, L. 3d Transition Metals for C-H Activation. Chem. Rev. 2019, 119, 2192-2452. (c) Kaga, A.; Chiba, S. Engaging Radicals in Transition Metal-Catalyzed CrossCoupling with Alkyl Electrophiles: Recent Advances. ACS Catal. 2017, 7, 4697-4706. (d) Milan, M.; Salamone, M.; Costas, M.; Bietti, M. The Quest for Selectivity in Hydrogen Atom Transfer Based Aliphatic C-H Bond Oxygenation. Acc. Chem. Res. 2018, 51, 1984-1995.

(9) For leading reviews on organic electrosynthesis, see: (a) Shatskiy, A.; Lundberg, H.; Kärkäs, M. D. Organic Electrosynthesis: Applications in Complex Molecule Synthesis. ChemElectroChem 2019, 6, 4067-4092. (b) Möhle, S.; Zirbes, M.; Rodrigo, E.; Gieshoff, T.; Wiebe, A.; Waldvogel, S. R. Modern Electrochemical Aspects for the Synthesis of Value-Added Organic Products. Angew. Chem., Int. Ed. 2018, 57, 6018-6041. (c) Yan, M.; Kawamata, Y.; Baran, P. S. Synthetic Organic Electrochemical Methods Since 2000: On the Verge of a Renaissance. Chem. Rev. 2017, 117, 13230-13319. (d) Kärkäs, M. D. Electrochemical Strategies for C-H Functionalization and C-N Bond Formation. Chem. Soc. Rev. 2018, 47, 5786-5865.

(10) For leading reviews on photoredox catalysis, see: (a) Shaw, M. H.; Twilton, J.; MacMillan, D. W. C. Photoredox Catalysis in Organic Chemistry. J. Org. Chem. 2016, 81, 6898-6926. (b) Kärkäs, M. D.; Porco Jr, J. A.; Stephenson, C. R. J. Photochemical Approaches to Complex Chemotypes: Applications in Natural Product Synthesis. Chem. Rev. 2016, 116, 9683-9747. (c) Romero, N. A.; Nicewicz, D. A. Organic Photoredox Catalysis. Chem. Rev. 2016, 116, 10075-10166.

(11) (a) Wu, G.; Wang, J.; Liu, C.; Sun, M.; Zhang, L.; Ma, Y.; Cheng, R.; Ye, J. Transition Metal-Free, Visible-Light-Mediated Construction of $\alpha, \beta$-Diamino Esters via Decarboxylative Radical Addition at Room Temperature. Org. Chem. Front. 2019, 6, 2245-2249. (b) Yoshimi, Y.; Kobayashi, K.; Kamakura, H.; Nishikawa, K.; Haga, Y.; Maeda, K.; Morita, T.; Itou, T.; Okada, Y.; Hatanaka, M. 
Addition of Alkyl Radicals, Generated from Carboxylic Acids via Photochemical Decarboxylation, to Glyoxylic Oxime Ether: A Mild and Efficient Route to $\alpha$-Substituted $\alpha$-Aminoesters. Tetrahedron Lett. 2010, 51, 2332-2334.

(12) Garrido-Castro, A. F.; Choubane, H.; Daaou, M.; Maestro, M. C.; Alemán, J. Asymmetric Radical Alkylation of $\mathrm{N}$-Sulfinimines under Visible Light Photocatalytic Conditions. Chem. Commun. 2017, 53, 7764-7767.

(13) For selected reviews on the use of chiral sulfoxides in asymmetric synthesis, see: (a) Han, J.; Soloshonok, V. A.; Klika, K. D.; Drabowicz, J.; Wzorek, A. Chiral Sulfoxides: Advances in Asymmetric Synthesis and Problems with the Accurate Determination of the Stereochemical Outcome. Chem. Soc. Rev. 2018, 47, 1307-1350. (b) Carreño, M. C.; Hernández-Torres, G.; Ribagorda, M.; Urbano, A. Enantiopure Sulfoxides: Recent Applications in Asymmetric Synthesis. Chem. Commun. 2009, 6129-6144.

(14) Ni, S.; Garrido-Castro, A. F.; Merchant, R. R.; deGruyter, J. N.; Schmitt, D. C.; Mousseau, J. J.; Gallego, G. M.; Yang, S.; Collins, M. R.; Qiao, J. X.; Yeung, K.-S.; Langley, D. R.; Poss, M. A.; Scola, P. M.; Qin, T.; Baran, P. S. A General Amino Acid Synthesis Enabled by Innate Radical CrossCoupling. Angew. Chem., Int. Ed. 2018, 57, 14560-14565.

(15) Yoshimi, Y. Photoinduced Electron Transfer-Promoted Decarboxylative Radical Reactions of Aliphatic Carboxylic Acids by Organic Photoredox System. J. Photochem. Photobiol. A: Chemistry 2017, 342, 116-130.

(16) Chu, L.; Ohta, C.; Zuo, Z.; MacMillan, D. W. C. Carboxylic Acids as a Traceless Activation Group for Conjugate Additions: A Three-Step Synthesis of ( \pm )-Pregabalin. J. Am. Chem. Soc. 2014, 136, 10886-10889.

(17) Shang, T.-Y.; Lu, L.-H.; Cao, Z.; Liu, Y.; He, W.-M.; Yu, B. Recent Advances of 1,2,3,5Tetrakis(carbazol-9-yl)-4,6-dicyanobenzene (4CzIPN) in Photocatalytic Transformations. Chem. Commun. 2019, 55, 5408-5419. 
(18) Margrey, K. A.; Nicewicz, D. A. A General Approach to Catalytic Alkene Anti-Markovnikov Hydrofunctionalization Reactions via Acridinium Photoredox Catalysis. Acc. Chem. Res. 2016, 49, 1997-2006.

(19) (a) Huang, W.; Ye, J.-L.; Zheng, W.; Dong, H.-Q.; Wei, B.-G. Radical Migration-Addition of N-tertButanesulfinyl Imines with Organozinc Reagents. J. Org. Chem. 2013, 78, 11229-11237. (b) Matos, J.L.M.; Vásquez-Céspedes, S.; Gu, J.; Oguma, T.; Shenvi, R.A. Branch-Selective Addition of Unactivated Olefins into Imines and Aldehydes. J. Am. Chem. Soc. 2018, 140, 16976-16981.

(20) (a) Kammer, L. M.; Rahman, A.; Opatz, T. A Visible Light-Driven Minisci-Type Reaction with NHydroxyphthalimide Esters. Molecules 2018, 23, 764. (b) Davies, J.; Angelini, L.; Alkhalifah, M. A.; Malet Sanz, L.; Sheikh, N. S.; Leonori, D. Photoredox Synthesis of Arylhydroxylamines from Carboxylic Acids and Nitrosoarenes. Synthesis 2018, 50, 821-830.

(21) (a) Viso, A.; Fernández de la Pradilla, R.; García, A.; Flores, A. $\alpha, \beta$-Diamino Acids: Biological Significance and Synthetic Approaches. Chem. Rev. 2005, 105, 3167-3196. (b) Wang, J.; Zhang, L.; Jiang, H.; Liu, H. Most Efficient Routes for the Synthesis of $\alpha, \beta$-Diamino Acid-Derived Compounds. Current Pharmaceutical Design 2010, 16, 1252-1259.

(22) Fernández-Salas, J. A.; Maestro, M. C.; Rodríguez-Fernández, M. M.; García-Ruano, J. L.; Alonso, I. Intermolecular Alkyl Radical Additions to Enantiopure N-tert-Butanesulfinyl Aldimines. Org. Lett. 2013, 15, 1658-1661.

(23) Note, that the excited state of the acridinium photocatalyst is a biradical and is better represented as $\mathrm{Acr}^{-}-\mathrm{Mes}^{*}$, see the following paper for details: Fukuzumi, S.; Ohkubo, K. Organic Synthetic Transformations Using Organic Dyes as Photoredox Catalysts. Org. Biomol. Chem. 2014, 12, 6059-6071.

(24) (a) Uraguchi, D.; Kinoshita, N.; Kizu, T.; Ooi, T. Synergistic Catalysis of Ionic Brønsted Acid and Photosensitizer for a Redox Neutral Asymmetric $\alpha$-Coupling of $\mathrm{N}$-Arylaminomethanes with Aldimines. J. Am. Chem. Soc. 2015, 137, 13768-13771. (b) Kizu, T.; Uraguchi, D.; Ooi, T. 
Independence from the Sequence of Single-Electron Transfer of Photoredox Process in RedoxNeutral Asymmetric Bond-Forming Reaction. J. Org. Chem. 2016, 81, 6953-6958. 